\title{
A SOON AND DISTANT CHRISTMAS
}

\author{
It's all in the delivery.
}

\section{BY NATHAN INSEL}

$\mathrm{T}$ he parking lot is a field of frustration. We get lucky: a pod unexpectedly pulls out in front of us and we zip in. Another pod coming from the other direction had apparently been waiting for the spot, and when we get out the driver gives us the finger.

"Mum, did you see what he did!" Masson is excited.

"Just ignore him," Cheryl says.

I ask Masson if he wants to jog to the entrance, but Cheryl gives me a look. "Do you want to get run over?" Sensors on the pods make that nearly impossible but we agree to walk together, happy to have escaped the competitive prowl for parking.

The relief is short-lived: the inside of the mall is busier than a water station on Sunday. We don't get ten paces before Cheryl is distracted by a stylish winter vest. I'm more impressed by the mannequin wearing it, which cycles through several moderately seductive poses. "Honey," I say, "let's stay focused. Keep to the list. Otherwise..." I look at Masson, "we may become mall rats and spend the rest of our lives hunting for cheese in the food court." He laughs.

We split up so that I can take care of Masson's gifts. His list isn't long. There's a video game and two movies that can be downloaded from the Internet. There's a set of mutant wrestler action figures that can be built with the 3-D printer. But what he wants more than anything can only be found at the toy store - a caterpillar-like robot with the label AIBUG!.

The toy store feels like a mosh pit. I push myself through and take a number. An hour and three v-pings with Cheryl later, the store runs out of AIBUG!s. What a mess. It's yet another reminder that society hasn't recovered from the collapse of the postal system. Saturated with technology and yet we can't seem to reorganize a simple packagedelivery system. In progress we regress, and tumble into the future.

Two hundred years later: a new generation of workers emerge from pupae and fan out in flight from caverns beneath Greenland. It is their first exposure to wind, but the nervous system quickly fills in details left blank by genetic memory. Although it is only their first flight, it is also their last. By the next

rotation of Earth, each worker will have liquefied into a blanket of mulch, providing sustenance to the next generation. In this way the colony propagates itself. The unsuccessful workers, those who fail to return engorged with digestible compounds, will

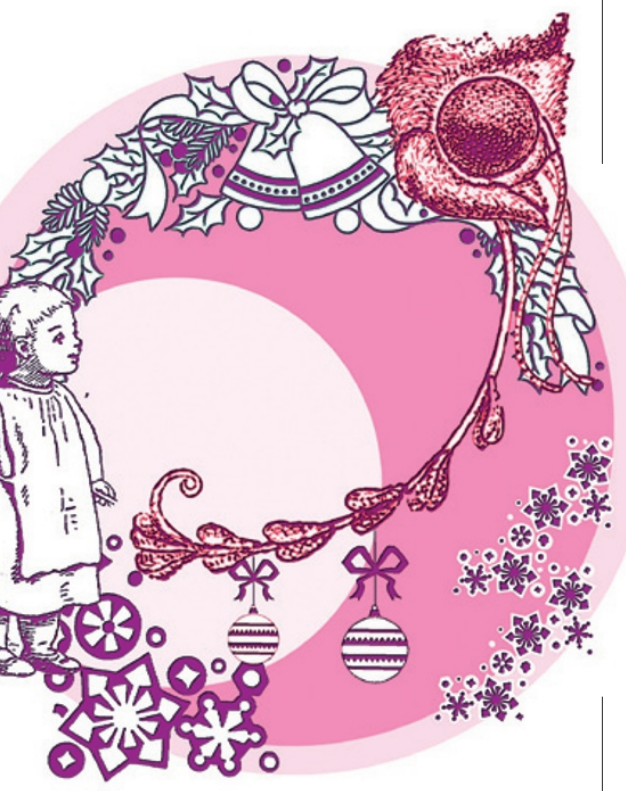

pass on only starved, frozen eggs that mark the terminus of a lineage.

But thoughts beyond this night have no purpose. Tonight the worker hunts. Internal molecular dances crescendo into physiological combustion. The worker's 32 ventral, rope-like extensions crawl forward, tasting the air and stabilizing flight. Its dorsal extensions form a rigid, branching meshwork, which triangulates light from stars while integrating code-embedded radio waves.

Two weeks after the shopping-mall mishap, I'm at home with Cheryl, my hands rolling around an AIBUG! box delivered by a stranger moments earlier. The toy arrived in the final hour, and I can't completely halt the inertia of my worry.

"Yes, we got it," I say. "But the fact is that crowdsourced delivery doesn't work, at least not during the holidays. It takes too long, things get lost. It's a crummy system. We need something more, well, sustainable."

"Sustainable?" Cheryl says. "I thought

$\rightarrow$ NATURE.COM

Follow Futures: @NatureFutures

f go.nature.com/mtoodm your big issue was 'adaptability'. Are you saying that the two are the same?"

"Well, no. Or maybe it's unsustainable that we don't automatically adapt. Postal delivery is one of the oldest social structures we have, how could it reach this level of dysfunction?"

"And you think having to wait two weeks for a toy is dysfunctional? Here's an idea: make it your next grant proposal, to bioengineer a package-delivery system. Seems like the logical step after your biotic waterfiltration system, don't you think so?"

I chuckle, she's got me. "Of course. I'll get right on that."

I continue to stare at the AIBUG! package in my hands. The solution to everything: mix together some nucleotides, bake with speeded reproductive rates, voilà! Instant biological package-delivery system. Dot com. As if making bacteria to purify water didn't require decades, multiple labs and millions of dollars. I am good friends with a DARPA rep, this will give him a laugh. I still have a dozen things to finish before bed, but instead I continue to stare at the robot toy, drawing out details of an absurd engineering project. I eat the plate of cookies for Santa that Masson had set out, and by the time I go to bed I find myself thinking: "Maybe..."

One worker flies west. The atmosphere compels it towards large structures filled with strange, complex composites. The worker's red proboscis creeps delicately but with unnatural speed, binding and engulfing the objects. From the largest structures it then targets the smaller; its ventral extensions optimize silence during the abrupt landings. White sensory cilia guide its proboscis down through the structure towards a unique and unmistakable combination of sugars and fats. But before reaching these, the organism is arrested by an allergy that forces it to regurgitate some of its gut contents.

Once in a while, the worker isn't fast enough. One time in a million, the landing is too loud, or the proboscis stalls too long by the allergenic pine. A bipedal child strays near the red, cilia-draped proboscis and then stops, awed. The worker reacts reflexively - not in attack, but to soothe the smaller organism with a low-frequency, calming call: "Ho, ho, ho." -

Nathan Insel claims to be a neuroscientist studying how the brain uses expectations to motivate behaviour. He also teaches at the University of Toronto and now apparently writes science fiction. 